\title{
川中丘陵区水稻田土壤呼吸及其影响因素
}

\author{
韩广轩 ${ }^{12}$ 朱 波 $^{2 *}$ 江长胜 ${ }^{3}$ \\ (1 中国科学院成都山地灾害与环境研究所,成都 610041)
}

(2 中国科学院植物研究所植被数量生态学重点实验室, 北京 100093) (3 中国科学院大气物理研究所, 北京 100029)

摘 要 基于川中丘陵区 2003 年 $4 \sim 9$ 月水稻田土壤呼吸、土壤温度和水稻( Oryza sativa) 生物量的测定 , 研究了水 稻田土壤呼吸日变化和季节变化特征以及影响稻田土壤呼吸的主要因素。结果表明, 水稻田土壤 $\mathrm{CO}_{2}$ 排放通量的 日变化为单峰型, 其最小值和最大值分别出现在当地时间 7:00 和 $15: 00$; 在水稻生长期内 稻田土壤 $\mathrm{CO}_{2}$ 排放通量 在 $18.00 \sim 269.69 \mathrm{mg} \mathrm{m}^{-2} \mathrm{~h}^{-1}$ 之间波动, 平均排放通量为 $121.76 \mathrm{mg} \mathrm{m}^{-2} \mathrm{~h}^{-1}$ 。在日的时间尺度上, 水稻田土壤 $\mathrm{CO}_{2}$ 排放通量与 $5 \mathrm{~cm}$ 土壤温度存在显著的指数函数关系; 而从整个生长期时间尺度上看, 水稻田土壤 $\mathrm{CO}_{2}$ 的排放 通量主要受到 $5 \mathrm{~cm}$ 土壤温度和水稻地下生物量的影响。在水稻生长初期, 水稻地下生物量与稻田土壤 $\mathrm{CO}_{2}$ 排放通 量之间存在着显著的相关关系 水稻拔节中后期到成熟期 , 土壤温度则是制约稻田土壤 $\mathrm{CO}_{2}$ 排放的关键因素。 $\mathrm{CO}_{2}$ 排放通量与稻田地表水层深度的相关关系不显著。

关键词 土壤呼吸 稻田 影响因素

\section{SOIL RESPIRATION AND ITS CONTROLLING FACTORS IN RICE FIELDS IN THE HILL REGION OF THE CENTRAL SICHUAN BASIN}

\author{
HAN Guang-Xuan ${ }^{12}$ ZHU Bo ${ }^{2 *}$ and JIANG Chang-Sheng ${ }^{3}$ \\ (1 Institute of Mountain Hazards and Environment, Chinese Academy of Sciences , Chengdu 610041 , China) \\ (2 Laboratory of Quantitative Vegetation Ecology , Institute of Botany , Chinese Academy of Sciences , Beijing 100093 , China) \\ (3 Institute of Atmospheric Physics, Chinese Academy of Sciences , Beijing 100029 , China)
}

\begin{abstract}
Measurements of soil respiration, soil temperature and rice biomass were made during the rice growing season in the hill region of the central Sichuan Basin from April to September 2003. Characteristics of the daily and seasonal variations of soil respiration and their controlling factors are presented. The results showed that daily variations of soil respiration could be modeled with a single peak curve. The minimum and maximum soil respiration values from rice fields occurred at 7:00 and 15:00, respectively. Daily soil respiration rates were highly correlated with $5 \mathrm{~cm}$ depth soil temperature measurements. The mean rate of soil respiration was $121.76 \mathrm{mg} \mathrm{m}^{-2} \mathrm{~h}^{-1}$, ranging from 18.00 to $269.69 \mathrm{mg} \mathrm{m}^{-2} \mathrm{~h}^{-1}$ during the growing season. Rice root biomass and $5 \mathrm{~cm}$ depth soil temperatures were the major factors influencing soil $\mathrm{CO}_{2}$ emissions during the entire growing season. There was a significant relationship between the rate of soil respiration and root biomass of rice during the initial growing season. From the middle/late stages to mature stage , $5 \mathrm{~cm}$ depth soil temperatures played a key role in regulating soil $\mathrm{CO}_{2}$ emissions from rice fields, while the relationship between the rate of soil respiration and water levels in the rice fields was not obvious.
\end{abstract}

Key words Soil respiration , Rice field , Controlling factors

土壤呼吸是陆地生态系统向大气层碳 $(\mathrm{C})$ 输入 的主要途径(Schimel, 1995) , 在全球碳循环中起着关 键作用 (IPCC，2001)。据预测, 到 2100 年全球气温
将升高 $1 \sim 6{ }^{\circ} \mathrm{C}$ ( IPCC, 2001$)$,进而导致土壤呼吸速 率的增加 (Grace \& Rayment, 2000)。土壤呼吸速率 相对小的改变都会显著改变大气中 $\mathrm{CO}_{2}$ 的浓度和土

收稿日期 : 2005-06-13 接受日期 : 2005-09-08

基金项目 : 国家重点基础研究发展计划项目 (2005CB121108)、国家自然科学基金重点项目 (40331014)和中国科学院知识创新工程重大项目 (KZCX1-SW-01-01B)

感谢中国科学院大气物理研究所王跃思研究员和郑循华研究员为本实验提供的仪器设备和对本实验设置的精心指导 感谢大气物理研究 所刘广仁高级工程师和博士生王迎红、孙扬对实验仪器的架设和维护

* 通讯作者 Author for correspondence E-mail : bzhu@imde.ac.cn

E-mail of the first author : gxhan@ibcas.ac.cn 
壤碳的累积速率 (Richard et al. ,2004) ,正因为如此 土壤呼吸一直成为全球碳循环研究的重点 (Raich \& Schlesinger , 1992)。

土壤呼吸受多种因素的共同影响，包括土壤温 度、土壤湿度、植被类型、土壤有机质、净生态系统生 产力 ( NEP) 、地上和地下生物量的分配、种群和群落 的相互作用和人类干扰等( Rustad et al. ,2000)。其 中, 土壤温度和土壤湿度是影响土壤呼吸的最重要 环境因子 (Raich \& Schlesinger, 1992 ; Davidson et al. , 1998 ; Maier \& Kress , 2000 ; Pangle \& Seiler, 2002) 土壤呼吸的大部分变化可由土壤温度和湿度 共同解释 (Burton \& Pregitzer, 2003)。土壤呼吸与土 壤温度具有良好的相关性, 在多种不同类型的生态 系统中, 土壤呼吸速率往往都是随土壤温度增加而 增大 (Davidson et al . 2000) , 其响应方程有多种类 型, 包括指数方程、线性方程、二次方程和逻辑斯蒂 方程等 (Fang \& Moncrieff, 2001)。土壤湿度是影响 土壤呼吸的另一重要因子, 土壤湿度不仅影响根系 呼吸和微生物呼吸, 同时还影响 $\mathrm{CO}_{2}$ 在土壤中的传 输, 因此土壤湿度对土壤呼吸的影响比较复杂 (Fang \& Moncrieff, 1999)。通常, 土壤湿度过低时会限制 微生物呼吸和根系呼吸 (Pangle \& Seiler, 2002 ; Yuste et al. , 2003) ,而土壤水分过高时会阻塞土壤空隙, 减少土壤中的 $\mathrm{O}_{2}$ 浓度, 限制 $\mathrm{CO}_{2}$ 的释放 (Bouma $e t$ $a l$. , 1997 ; Bouma \& Bryla , 2000) , 在土壤湿度适中 时, 水分对土壤呼吸速率无明显影响 (Fang \& Moncrieff, 2001)。目前, 有关土壤呼吸的研究主要集中 在森林生态系统、草原生态系统, 而对农田生态系统 土壤呼吸的测定研究较少, 从而制约着国家尺度的 碳蓄积和碳排放的准确估算以及增汇减源措施的实 施(于贵瑞 2003)。

农田生态系统是人类活动最活跃的部分，作为 受人类活动干扰最为频繁和严重的生态系统, 它的 $\mathrm{CO}_{2}$ 排放状况如何对于认识和了解陆地生态系统碳 循环机制及其温室气体减排方案的制定具有重要的 意义。稻田作为一种特殊的生态系统 (长时间淹水 和人为管理), 研究稻田土壤呼吸及其影响因素对于 估算农田生态系统碳收支有着重要意义。梁巍等 (2003) 研究了黑龙江黑土稻田土壤呼吸, 发现在水 稻( Oryza sativa) 生长前期, 土壤呼吸强度增大, 随后 略有下降, 接着又逐渐增加; 在水稻生长初期, 长效 尿素能显著抑制土壤呼吸。邹建文等 (2003) 发现， 稻田土壤呼吸主要受土壤水分状况 (土壤水分管理) 的驱动，土温也是影响土壤 $\mathrm{CO}_{2}$ 排放量的重要因子，
同时稻田 $\mathrm{CO}_{2}$ 排放与水层深度呈弱的负相关关系。 王子芳等 (2003) 研究了 10 年水旱轮作对稻田土壤 呼吸的影响, 发现在水稻生长期, 水旱轮作田的土壤 呼吸强度比长期淹水稻田高。

这些研究主要集中在环境因子和田间管理 (水 分和施肥管理)对稻田土壤呼吸的影响上, 而水稻生 长对土壤呼吸的影响尚少见报道。本文利用静态箱 /气相色谱法对川中丘陵区稻田土壤呼吸进行水稻 全生长季的观测, 同时测定了土壤温度、水深和水稻 生物量的动态变化, 试图阐述两个问题：

1) 水稻生长期内稻田土壤呼吸是如何变化的? 2) 生物量、土壤温度和水深如何共同影响稻田土壤 呼吸?

\section{1 材料和方法}

\section{1 试验地点}

试验于 2003 年 $4 \sim 9$ 月在中国科学院盐亭紫色 土农业生态实验站进行。该试验站位于 $105^{\circ} 27^{\prime} \mathrm{E}$, $31^{\circ} 16^{\prime} \mathrm{N}$, 海拔 $410 \mathrm{~m}$, 属于中亚热带季风气候, 年均 气温 $17.3{ }^{\circ} \mathrm{C}$, 多年平均降雨量 $826 \mathrm{~mm}$ 。

试验田长期以 油菜-水稻” 轮作为主, 稻油轮作 是本区最具有代表性的耕作制度。试验田的土壤为 侏罗纪蓬莱镇紫色砂页岩风化物基础上发育的水稻 土, 土壤 $\mathrm{pH}$ 值 8.17 , 有机质 $1.93 \mathrm{~g} \mathrm{~kg}^{-1}$, 全氮 0.12 $\mathrm{g} \mathrm{kg}^{-1}$, 碱解氮 $97.77 \mathrm{mg} \cdot \mathrm{kg}^{-1}$, 有效磷 28.86 $\mathrm{mg} \mathrm{kg}{ }^{-1}$, 有效钾 $147.95 \mathrm{mg} \mathrm{kg}^{-1}$ 。

水稻品种为 $I I$ 优'。5 月 10 日播种, 10 月 24 日收割。氮肥品种为碳酸氢铵, 磷肥品种为过磷酸 钙, 水稻生长季用量分别为 $133 \mathrm{~kg} \mathrm{~N} \mathrm{hm}{ }^{-2}$ 和 $120 \mathrm{~kg}$ $\mathrm{P}_{2} \mathrm{O}_{5} \mathrm{hm}^{-2}$,所有肥料在移栽前一次性施到田中。

\section{2 土壤呼吸测定}

采样箱由顶箱和地箱两部分组成。顶箱为柱 型, 用 PVC 材料制成, 高 $30 \mathrm{~cm}$ 地箱为四面体, 横截 面为 $60 \mathrm{~cm} \times 20 \mathrm{~cm}$ 深度 $3 \mathrm{~cm}$, 水稻行距为 $20 \mathrm{~cm}$, 底 座刚好放置在水稻行距之间。地箱下部深入土壤 3 $\mathrm{cm}$ 以利于水稻根系生长, 减少对水稻根系的干扰。 地箱上端有密封水槽, 采样时将顶箱安装在地箱上, 地箱水槽内加水密封。密封后立即用 $15 \mathrm{ml}$ 注射器 从箱内抽取 $15 \mathrm{ml}$ 气体, 密封 $15 \mathrm{~min}$ 内每隔 $5 \mathrm{~min}$ 取 样 1 次，并准确记录采样时间。采样结束后，立即移 开采样箱。样品采用 CA-5 气体样品进样仪进样 利 用 HP5890 II 型气相色谱仪进行分析。色谱柱填料 采用高纯氮气作为载气, $\mathrm{CO}_{2}$ 检测器为氢火焰离子 化检测器 (FID), 检测器温度为 $200{ }^{\circ} \mathrm{C}$, 炉温为 
$55{ }^{\circ} \mathrm{C}$ 。每周对土壤呼吸进行 2 次观测, 时间为上午 $9: 00 \sim 11: 00$ 。同时, 分别在 5.7 和 9 月选择一个晴 天进行土壤呼吸的日变化观测, 具体采样时间为在 7:00 19:00, 每隔 $2 \mathrm{~h}$ 采样 1 次 (7 次采样)。同期 用 JM 便携式测温表测定箱内温度和 $5 \mathrm{~cm}$ 地温等环 境要素, 并记录田间地表水深。

\section{3 生物量}

每 $15 \mathrm{~d}$ 左右一次性采集完整的水稻植株地上 和地下部分鲜样, 并记录植株数, 使用通风高温烘炉 在 $105{ }^{\circ} \mathrm{C}$ 下杀青, $70{ }^{\circ} \mathrm{C}$ 下烘干至恒重, 在采样日同 时测定植株密度, 计算水稻的生物量。

\section{4 土壤呼吸计算}

气体的通量表示单位时间单位面积观测箱内该 气体质量的变化。 $\mathrm{CO}_{2}$ 通量采用下式计算：

$$
F=\frac{1.2 \times 10^{-4} \times P \times H}{273.15+t} \frac{d c}{d t}
$$

式中 : $F$ 为 $\mathrm{CO}_{2}$ 排放通量, 单位为 $\mathrm{mg} \mathrm{m}^{-2} \mathrm{~h}^{-1} ; t$ 为 每次采样 $15 \mathrm{~min}$ 内箱内温度的平均值, 单位为 ${ }^{\circ} \mathrm{C} ; P$ 为采样点的气压 (bar); $H$ 为采样时采样箱高度与箱 底水深的差值, 单位为 $\mathrm{cm}$ 。

\section{2 结果与分析}

\section{1 土壤呼吸的日动态}

水稻分䔉期 (5 月 28 日) 、抽穗扬花期 (7 月 22 日)和成熟期 (9 月 5 日) 的稻田土壤呼吸日动态表 明(图 1), 土壤呼吸在水稻不同生长期具有相似的 日变化趋势, 表现明显的单峰型, 最小值都出现在 7:00左右, 最大值都出现在 15:00 左右, 这与周志田 等(2002)的研究结果相同。稻田土壤呼吸在水稻分 蕉期、抽穗扬花期和成熟期的日平均值分别为 124.03、135.82 和 $434.32 \mathrm{mg} \mathrm{m} \mathrm{m}^{-2} \mathrm{~h}^{-1}$ 。

\section{2 土壤呼吸日动态的影响因素}

对稻田土壤呼吸与 $5 \mathrm{~cm}$ 土壤温度 (图 2)、地表 温度、箱内温度和气温分别进行单因子相关分析 (表 1) 2003 年 5 月 28 日、7 月 22 日和 9 月 5 日的土壤 呼吸都与 $5 \mathrm{~cm}$ 土壤温度的相关关系显著。

5 月 28 日、7月 22 日和 9 月 5 日的稻田土壤呼 吸对 $5 \mathrm{~cm}$ 土壤温度的响应都表现为指数函数关系, 相关关系表达式为 :

$$
\begin{aligned}
& Y\left(\mathrm{CO}_{2}\right)=30.22 \mathrm{e}^{0.0519 X}, r^{2}=0.75 \\
& Y\left(\mathrm{CO}_{2}\right)=1.675 \mathrm{e}^{0.1725 X}, r^{2}=0.85 \\
& Y\left(\mathrm{CO}_{2}\right)=83.98 \mathrm{e}^{0.0696 X}, r^{2}=0.82
\end{aligned}
$$

式中, $Y$ 为 $\mathrm{CO}_{2}$ 排放速率 $\left(\mathrm{mg} \mathrm{m}^{-2} \mathrm{~h}^{-1}\right) ; X$ 为 $5 \mathrm{~cm}$ 土壤温度。以上 3 个关系式均通过 $p<0.01$ 限制性

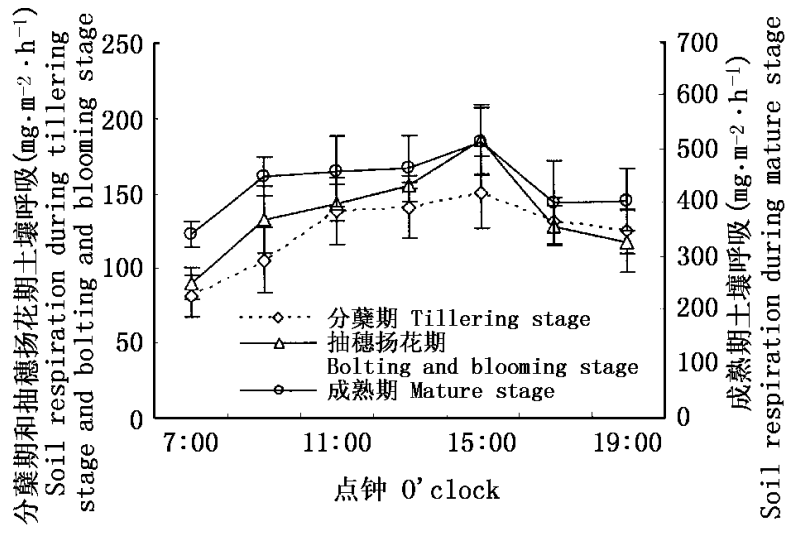

图 1 水稻不同生长期内稻田土壤 $\mathrm{CO}_{2}$ 排放的日动态 Fig.1 Daily variations of soil $\mathrm{CO}_{2}$ emission of rice at different bearing stages

检验。

\section{3 土壤呼吸的季节动态}

稻田土壤呼吸的季节性波动较大 (图 3)。水稻 移栽后, 随着水稻的生长, 稻田土壤 $\mathrm{CO}_{2}$ 排放通量逐 渐升高, 并持续到移栽后 $35 \mathrm{~d}$ 。这段时间土壤呼吸 与水稻地下生物量的变化趋势基本一致。移栽后 $35 \mathrm{~d}$ 至水稻收获, 稻田土壤 $\mathrm{CO}_{2}$ 排放通量虽有变化, 但总体上一直维持着相对较高的排放通量, 表现出 明显的波动, 其波动趋势与 $5 \mathrm{~cm}$ 土壤温度基本相 同, 并存在滞后效应。整个水稻生长期内 稻田土壤 $\mathrm{CO}_{2}$ 排放通量在 $18.00 \sim 269.69 \mathrm{mg} \mathrm{m}^{-2} \mathrm{~h}^{-1}$ 之间波 动, 其平均排放通量为 $121.76 \mathrm{mg} \mathrm{m}^{-2} \mathrm{~h}^{-1}$ 。水稻 返青期、分莘期、拔节期、抽穗期和成熟期内稻田土 壤 $\mathrm{CO}_{2}$ 平均排放通量分别为 $73.80 、 85.91 、 147.55$ 、 125.94 和 $175.30 \mathrm{mg} \mathrm{m}^{-2} \mathrm{~h}^{-1}$ 。

\section{4 水稻地下生物量对土壤呼吸的影响}

在水稻生长季内共进行了 10 次生物量的采集 (图 4)，通过回归分析，得出水稻地下生物量与移栽 后天数的回归方程，其表达式分别为：

$Y=-0.8218 X^{2}+130.97 X-1772.8, r^{2}=0.91$

式中, $Y$ 为地下生物量 $\left(\mathrm{kg} \mathrm{hm}^{-2}\right) ; X$ 为移栽后天数。 方程 (5) 的相关关系系数经显著性 $F$ 检验均达到 $p$ $<0.01$ 极显著水平。

根据回归方程 (5)计算出水稻生物量动态, 其生 长曲线呈抛物线型 (图 4)。农田生态系统中, 作物 在营养生长阶段生物量变化很大。水稻自移栽到移 栽后 $42 \mathrm{~d}$, 水稻地下生物量由 $56.05 \mathrm{~kg} \mathrm{hm}^{-2}$ 增加为 $2278.29 \mathrm{~kg} \mathrm{hm}^{-2}$ 。以后水稻地下生物量增长趋于 缓慢, 至移栽后 $78 \mathrm{~d}$ 地下生物量达到最大值, 为 $3443.03 \mathrm{~kg} \mathrm{hm}^{-2}$ 。进入灌浆期以后, 根系生物量趋 
表 1 土壤呼吸与各温度之间的相关关系

Table 1 Correlation relationship between soil respiration and different temperatures

\begin{tabular}{|c|c|c|c|c|}
\hline 日期 & $5 \mathrm{~cm}$ 土壤温度 & 地表温度 & 箱内温度 & 气温 \\
\hline Date & $5 \mathrm{~cm}$ soil temperature & Surface ground temperature & Air temperature in chamber & Air temperature \\
\hline 5 月 28 日 May 28 & $0.887^{* *}$ & $0.881^{* *}$ & $0.953^{* *}$ & $0.930^{* *}$ \\
\hline 7 月 22 日 July 22 & $0.913^{* *}$ & 0.672 & 0.752 & 0.743 \\
\hline 9 月 5 日 September 5 & $0.914^{* *}$ & 0.395 & 0.678 & 0.522 \\
\hline
\end{tabular}

**: 0.01 水平下显著相关 Correlation is significant at the 0.01 level (2-tailed)
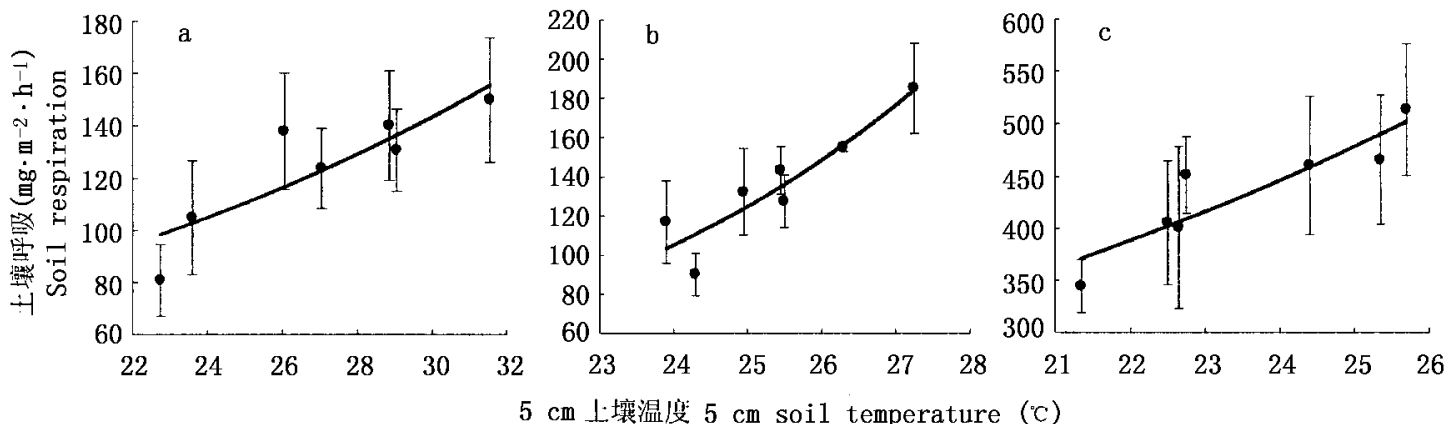

图 2 稻田土壤呼吸与 $5 \mathrm{~cm}$ 土壤温度的相关关系

Fig.2 Relationship between soil respiration from rice field and $5 \mathrm{~cm}$ soil temperature a 5 月 28 日 May 28 b 7 月 22 日 July 22 c 9 月 5 日 September 5

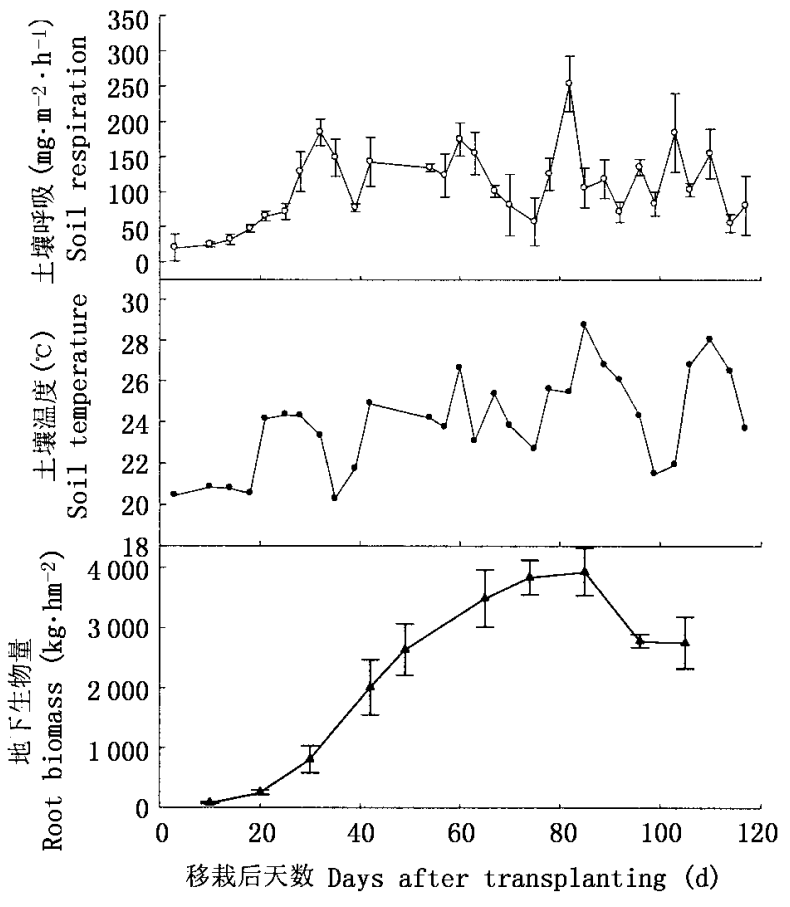

图 3 稻田土壤呼吸、 $5 \mathrm{~cm}$ 土壤温度和水稻地下生物量的季节变化

Fig. 3 Seasonal variations of soil respiration , $5 \mathrm{~cm}$ soil temperature and root biomass of rice

于减少,直到成熟期。

统计分析表明,自移栽到移栽后 $35 \mathrm{~d}$, 水稻地下 生物量与土壤呼吸之间存在着显著的指数函数关系
(图 5)：

$$
y=33.83 \mathrm{e}^{0.00093 x}, r^{2}=0.876
$$

式中, $y$ 为土壤呼吸 $\left(\mathrm{mg} \mathrm{m} \mathrm{m}^{-2} \mathrm{~h}^{-1}\right) ; x$ 为地下生物量 $\left(\mathrm{kg} \mathrm{hm}^{-2}\right)$ 。由此可见,在水稻生长前期, 水稻土壤 呼吸速率随生物量的增加而增加, 这与孙文娟等 (2004)的研究结果相同。

\section{5 土壤温度对稻田土壤呼吸的影响}

分析结果表明, 在水稻整个生长季内, 土壤呼吸 与土壤温度之间不存在显著的相关关系 (图 6)。但 在水稻拔节中后期 (移栽后 $42 \mathrm{~d}$ ) 至收获期间, 稻田 土壤 $\mathrm{CO}_{2}$ 排放的动态变化与 $5 \mathrm{~cm}$ 土壤温度动态基 本一致，但并不完全同步(图 3)。这是因为在稻田 中, 由于地表水层和土壤的缓冲作用, 地下土壤温度 的变化存在滞后性。通过回归分析, 得到水稻拔节 中后期至收获期间土壤呼吸与土壤温度的回归方程 (图 7)：

$$
y=21.55 \mathrm{e}^{0.07129 x}, r^{2}=0.375
$$

式中, $y$ 为土壤呼吸 $\left(\mathrm{mg} \mathrm{m} \mathrm{m}^{-2} \mathrm{~h}^{-1}\right) ; x$ 为土壤温度 $\left({ }^{\circ} \mathrm{C}\right)$ 。经 $F$ 检验, 变量与自变量的相关性达到了显 著水平, 说明在水稻生长后期, 土壤温度成为控制土 壤呼吸的关键因子。

\section{6 地表水深对稻田土壤呼吸的影响}

在水稻生长期内, 稻田的地表水深在 $0.5 \sim 7.8$ $\mathrm{cm}$ 波动。地表水深可以影响土壤中微生物的活性， 
还可以通过影响水稻的生长来间接影响根系生物量 和根系分泌物的变化, 另外, 水深还影响土壤中 $\mathrm{CO}_{2}$ 向大气中的排放。邹建文等 (2003) 研究发现在移栽 至烤田前的淹水阶段, 稻田 $\mathrm{CO}_{2}$ 排放主要受淹水水 层深度的制约。但是本试验中土壤呼吸速率与地表 水深之间并不存在显著的相关关系 (图 8)。这可能 是由于在水稻生长期内稻田都有水覆盖，同时与短 时间内水深变化的幅度不大有关。

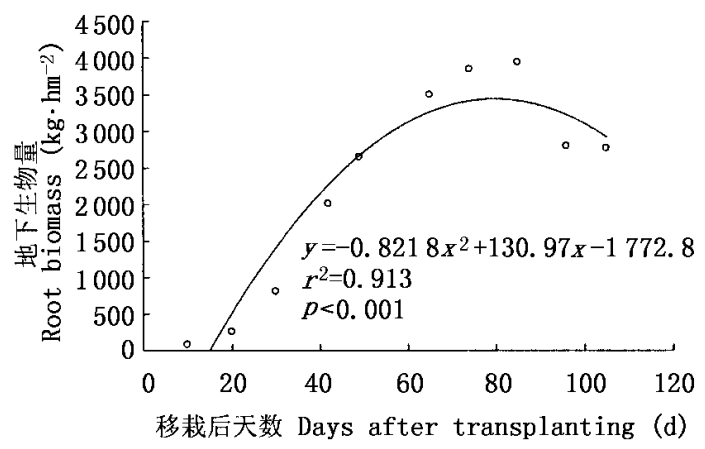

图 4 水稻地下生物量与移栽后天数的相关关系

Fig.4 Relationship between root biomass of rice and days after transplanting

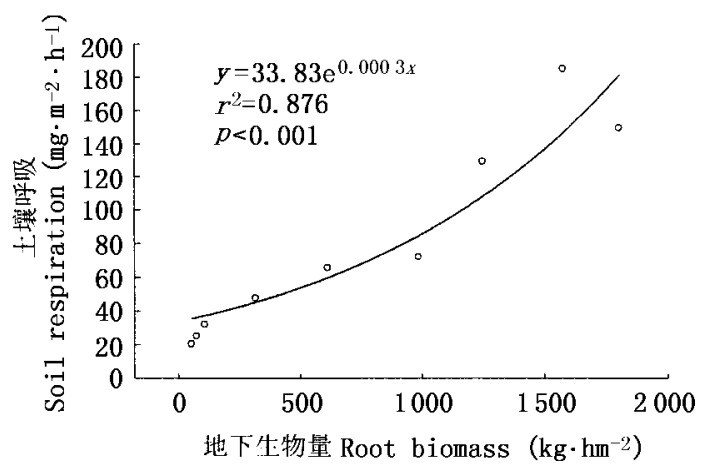

图 5 稻田土壤呼吸与水稻地下生物量的关系(自移栽到移栽后 $35 \mathrm{~d}$ ) Fig.5 Relationship between root biomass and soil respiration from rice field (from transplanting to 35 days after transplanting)

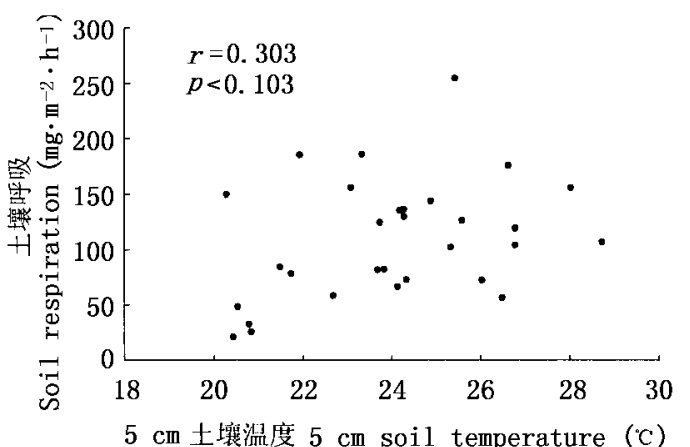

图 6 水稻生长季中稻田土壤呼吸与 $5 \mathrm{~cm}$ 土壤温度的相关关系

Fig.6 Relationship between soil respiration from rice field and $5 \mathrm{~cm}$ soil temperature during the growing season

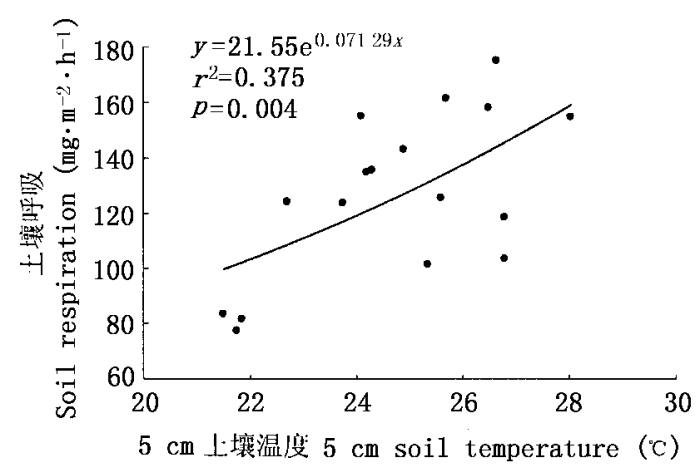

图 7 稻田土壤呼吸与 $5 \mathrm{~cm}$ 土壤温度的关系(自移栽后 $42 \mathrm{~d}$ 到收获)

Fig.7 Relationship between $5 \mathrm{~cm}$ soil temperature and soil respiration from rice field (from 42 days after transplanting to reaping)

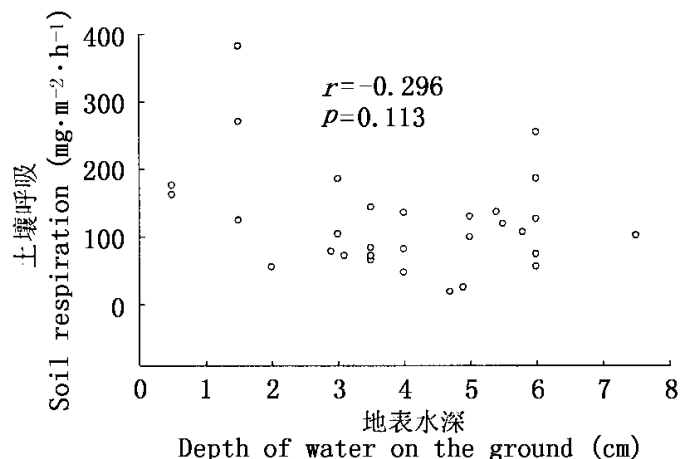

图 8 稻田土壤呼吸与地表水深的相关关系

Fig. 8 Relationship between soil respiration and depth of water on the ground

\section{3 结论与讨论}

实验结果表明, 稻田土壤呼吸有明显的日变化 和季节变化动态。稻田土壤呼吸日变化趋势与土壤 温度基本一致。在整个水稻生长期内, 稻田土壤 $\mathrm{CO}_{2}$ 排放通量在 $18.00 \sim 269.69 \mathrm{mg} \mathrm{m}^{-2} \mathrm{~h}^{-1}$ 之间波 动，其平均排放通量为 $121.76 \mathrm{mg} \mathrm{m}^{-2} \mathrm{~h}^{-1}$ 。环境 条件的时空变异性导致了土壤呼吸的季节动态 ( Elberling，2003）, 土壤碳模型研究通常认为土壤呼吸 受土壤温度的作用或土壤温度和土壤湿度的共同作 用(Davidson et al., 1998 ; Treonis et al .,2002)。然 而, 同时分析土壤温度、土壤湿度和其它影响因素 (比如土壤有机碳、根系等) 对土壤呼吸时空变异性 共同作用的研究还很缺乏 (Gough \& Seiler, 2004)。 本文同时分析土壤温度、地表水深和地下生物量对 稻田土壤呼吸的影响。

水稻移栽至水稻拔节前期 (移栽后 $35 \mathrm{~d}$ ) ,根系 成为影响稻田土壤 $\mathrm{CO}_{2}$ 排放通量的关键因素。根系 呼吸的贡献对植株旁的土壤呼吸是相当重要的 （Gough \& Seiler，2004），作物根系的参与大大促进了 
土壤呼吸作用(孙文娟等, 2004)。箱下的呼吸根会 直接影响土壤呼吸通量 (Hanson et al. , 2000), Wiseman 和 Seiler (2004)认为土壤呼吸的空间变异性是由 于各测点根系生物量的不同造成的，这从侧面说明 了地下生物量对土壤呼吸的影响。水稻生长初期根 系生长迅速, 根系呼吸强烈; 同时水稻根系分泌物的 增加导致土壤中有机质积累, 为微生物提供了大量 可利用的底物, 促进了土壤微生物呼吸 (梁巍等, 2003 孙文娟等, 2004)。

水稻拔节中后期到成熟期, 在水稻生物量变化 不大的前提下, 土壤温度是制约稻田土壤 $\mathrm{CO}_{2}$ 排放 的关键因素。土壤呼吸与温度的显著的相关性可以 解释为土壤呼吸主要来源于异养呼吸而受根系活动 的影响较小 (Tang et al , , 2003), 这是因为水稻生育 中后期水稻地上部和地下部生物量增长明显低于水 稻生育前期, 水稻植株已经发育到一定程度 根系生 物量变化幅度不大(图 5)。而 6 9 月土壤温度在 $21.5 \sim 28.8^{\circ} \mathrm{C}$ 之间波动, 土壤温度在地下生物量相 对稳定的基础上影响土壤呼吸。邹建文等 (2003) 研 究发现在稻田非淹水阶段 (烤田和湿润灌溉及落干 期) 稻田 $\mathrm{CO}_{2}$ 排放的总体变化趋势与土壤温度趋于 一致。在水稻生长前期, 水稻根系生长较快, 根系活 动强烈, 土壤呼吸受根系呼吸和异养呼吸共同影响, 土壤呼吸与温度的相关性会减小 ( Tang et al , , 2003)。

土壤温度还决定了土壤呼吸的日动态。这主要 由于稻田土壤在水稻生长期内长期淹水, 土壤水分 含量几近饱和状态, 同时水稻生物量变化在一天内 的变化也不大 影响稻田土壤呼吸的因子主要是土 壤温度, 这与其它的研究结果是相同的 (Mariko et al.2000;Frank et al.,2002 ;周志田等 ,2002)。土壤 温度直接影响植物根系呼吸和土壤微生物的活动, 土壤温度升高, 根系呼吸和土壤生物活性增强 (Jenkinson et al . , 1991) , 土壤中产生的 $\mathrm{CO}_{2}$ 增多 ; 同 时, 土壤温度影响土壤中 $\mathrm{CO}_{2}$ 向大气的输送过程 , 壤温度升高, $\mathrm{CO}_{2}$ 向大气的排放增强 (Tang et al., 2003)。

以上分析表明: 水稻地下生物量和土壤温度是 影响土壤呼吸的主要因素, 两者的交互作用影响着 稻田土壤呼吸的季节性变化。水稻移栽到拔节前 期, 水稻生长迅速, 土壤呼吸主要受水稻生长 (地下 生物量) 的影响; 水稻拔节中后期到成熟期, 水稻植 株的生物量动态变化不大, 温度是制约稻田土壤呼 吸的关键因素。温度和生物量对土壤呼吸的影响在
水稻的不同生长期是不同的, 这说明建立土壤呼吸 模型时, 应该分时间段分别分析温度和生物量对土 壤呼吸的影响, 比如根系生物量在生长前期与土壤 呼吸有关, 但是并不意味着生长后期土壤呼吸也遵 循相同的模式。

\section{参 考 文 献}

Bouma TJ, Bryla DR (2000). On the assessment of root and soil respiration for soils of different textures: interactions with soil moisture contents and soil $\mathrm{CO}_{2}$ concentrations. Plant and Soil, $227,215-221$.

Bouma TJ, Nielsen KL, Eissenstat DM, Lynch JP (1997). Estimating respiration of roots in soil: interactions with soil $\mathrm{CO}_{2}$, soil temperature, and soil water content. Plant and Soil, 195, 221 -232 .

Burton AJ, Pregitzer KS (2003) . Field measurements of root respiration indicate little to no seasonal temperature acclimation for sugar maple and red pine. Tree physiology, 23, 273-280 .

Davidson EA, Belk E, Boone RD (1998). Soil water content and temperature as independent or confounded factors controlling soil respiration in a temperate mixed hardwood forest. Global Change Biology, 4, 217 - 227.

Davidson EA, Trumbore SE, Amundson R (2000). Soil warming and organic carbon content. Nature, 408, $789-790$.

Elberling B (2003). Seasonal trends of soil $\mathrm{CO}_{2}$ dynamics in a soil subject to freezing. Journal of Hydrology, 276, 159- 175 .

Fang C, Moncrieff JB (1999). A model for soil $\mathrm{CO}_{2}$ production and transport. I. Model development. Agricultural and Forest Meteorology, 95, 225-236.

Fang C, Moncrieff JB (2001). The dependence of soil $\mathrm{CO}_{2}$ efflux on temperature. Soil Biology and Biochemistry, 33, 155 - 165 .

Frank AB, Liebig MA, Hanson JD (2002). Soil carbon dioxide fluxes in northern semiarid grasslands. Soil Biology and Biochemistry, 34, $1235-1241$.

Gough M, Seiler JR (2004). The influence of environmental, soil carbon, root, and stand characteristics on soil $\mathrm{CO}_{2}$ efflux in loblolly pine (Pinus taeda L.) plantations located on the South Carolina Coastal Plain Christopher. Forest Ecology and Management, 191, $353-363$.

Grace J, Rayment M (2000). Respiration in the balance. Nature, $404,819-820$.

Hanson PJ, Edwards NT, Garten CT, Andrews JA (2000). Separating root and soil microbial contributions to soil respiration: a review of methods and observations. Biogeochemistry, 48, 115 146.

IPCC (2001). Climate Change 2001. Third Assessment Report of the IPCC. Cambridge University Press, Cambridge, 183- 237.

Jenkinson DS, Adams DE, Wild A (1991). Model estimates of $\mathrm{CO}_{2}$ emission from soil in response to global warming. Nature, $351,304-306$. 
Liang W(梁巍), Yue J(岳进), Shi Y(史奕), Huang GH(黄国 宏), Liang ZB(梁战备) (2003). Seasonal variation of soil microbial biomass, respiration rate and $\mathrm{CH}_{4}$ emission in black earth rice fields. Chinese Journal of Applied Ecology (应用生态学 报), 14, 2278 - 2280. (in Chinese with English abstract)

Maier CA, Kress LW (2000). Soil $\mathrm{CO}_{2}$ evolution and root respiration in 11-year-old loblolly pine (Pinus taeda) plantations as affected by moisture and nutrient availability. Canadian Journal of Forest Research, 30, 347 - 359 .

Mariko S, Nishimura N, Mo W (2000). Winter $\mathrm{CO}_{2}$ flux from soil and snow surfaces in a cool-temperate deciduous forest. Ecological Research, 15, $363-372$.

Pangle RE, Seiler J (2002) . Influence of seedling roots, environmental factors and soil characteristics on soil $\mathrm{CO}_{2}$ efflux rates in a 2-year-old loblolly pine (Pinus taeda L.) plantation in the Virginia Piedmont. Environmental Pollution, 116, s85-s96.

Raich JW, Schlesinger WH (1992). The global carbon dioxide flux in soil respiration to vegetation. Tellus, 44(B), 81-99.

Richard DB, Eric D, Kathleen S (2004) . Chronic nitrogen additions reduce total soil respiration and microbial respiration in temperate forest soils at the Harvard Forest. Forest Ecology and Management, 196, 43 - 56.

Rustad LE, Huntington TG, Boone RD (2000). Controls on soil respiration: implications for climate change. Biogeochemistry, $49,1-6$.

Schimel DS (1995) . Terrestrial ecosystem and carbon-cycle. Global Change Biology, 1,77 99.

Sun WJ (孙文娟), Huang Y(黄耀), Chen ST(陈书涛), Yang $\mathrm{ZF}$ (杨兆芳), Zheng XH(郑循华) (2004). $\mathrm{CO}_{2}$ emission from soil-crop system as influenced by crop growth and tissue $\mathrm{N}$ content. Environmental Science (环境科学), 25(3), 1-6. (in Chinese with English abstract)

Tang JW, Dennis DB, Qi Y, Xu LK (2003). Assessing soil $\mathrm{CO}_{2}$ efflux using continuous measurements of $\mathrm{CO}_{2}$ profiles in soils with small solid-state sensors. Agricultural and Forest Meteorology, $118,207-220$.

Treonis AM, Wall DH, Virginia RA (2002). Field and microcosm studies of decomposition and soil biota in a cold desert soil. $E$ cosystems, 5, $159-170$.

Wang ZF (王子芳), Gao M (高明), Qin JC (秦建成), Ci E (慈恩) (2003). Effect of long-term“ paddy-upland” rotation on soil fertility of paddy fields. Journal of Southwest Agricultural University (Natural Science Edition) (西南农业大学学报(自然科 学版) ), 25, 514-521. (in Chinese with English abstract)

Wiseman PH, Seiler JR (2004). Soil $\mathrm{CO}_{2}$ efflux across four age classes of plantation loblolly pine (Pinus taeda L.) on the Virginia Piedmont. Forest Ecology and Management, 192, 297 311 .

Yu GR(于贵瑞) (2003). Global Change, Carbon Cycle and Storage in Terrestrial Ecosystem (全球变化与陆地生态系统碳循 环和碳蓄积). China Meteorological Press, Beijing, 1-4. (in Chinese)

Yuste JC, Janssens IA, Carrara A, Meiresonne L, Ceulemans R (2003). Interactive effects of temperature and precipitation on soil respiration in a temperate maritime pine forest. Tree Physiology, 23, $1263-1270$.

Zhou ZT(周志田), Cheng SK(成升魁), Liu YF(刘允芬), Li JY (李家永) (2002). $\mathrm{CO}_{2}$ emission of soil under different landuse types in subtropical red soil hilly areas in China: preliminary exploration. Resources Science (资源科学), 24(2), 83-87. (in Chinese with English abstract)

Zou JW(邹建文)，Huang Y(黄耀)，Zong LG(宗良纲)，Zheng XH(郑循华), Wang YS (王跃思) (2003). A field study on $\mathrm{CO}_{2}, \mathrm{CH}_{4}$ and $\mathrm{N}_{2} \mathrm{O}$ emissions from rice paddy and impact factors. Acta Scientiae Circumstantiae (环境科学学报), 23, 758 - 764 . (in Chinese with English abstract) 